\title{
El racecadotril fue efectivo como coadyuvante en el tratamiento de la diarrea aguda en niños
}

Racecadotril in the treatment of acute watery diarrhea in children.

Salazar-Lindo E, Santisteban-Ponce J, Chea-Woo E. N Engl J Med 2000; 343:463-7.

\section{Objetivo}

Evaluar la eficacia del agregado de racecadotril a las sales de rehidratación oral (SRO) en el tratamiento de la diarrea aguda acuosa en niños de un país en vías de desarrollo.

\section{Diseño}

Ensayo clínico randomizado, doble ciego, controlado con placebo, realizado en un centro único.

\section{Lugar}

Realizado por el Departamento de Pediatría del Hospital Nacional Cayetano Heredia de Lima, Perú.

\section{Pacientes}

De 1994 a 1998 se incluyeron 135 niños de entre 3 y 35 meses de edad con diarrea de hasta 5 días de duración hospitalizados por deshidratación. Los pacientes debían tener 3 o más deposiciones en las últimas 24 hs y por lo menos una en las 6 hs posteriores al ingreso. No se incluyeron niñas por la dificultad técnica en la recolección de muestras.

Se excluyeron los niños con diarrea sanguinolenta y que tuvieran las contraindicaciones usuales para la terapia de rehidratación oral (TRO).

\section{Intervención}

Se aleatorizó racecadotril. o placebo cada 8 hs, sumado a las SRO, que se les administró a todos los pacientes.

El tratamiento se realizó hasta que cesara la diarrea, definido como presencia de deposiciones formadas en dos oportunidades o ausencia de deposiciones en las últimas 12 hs.

Todos los niños fueron alimentados durante el tratamiento.

No fue permitido el uso de antibióticos, aspirina o antidiarreicos; de haber sido necesarios o haber diarrea sanguinolenta, el paciente se excluía del estudio.

En la admisión hospitalaria se realizaron búsquedas para patógenos bacterianos y Rotavirus.

\section{Medición de resultados principales}

El punto final primario fue el peso de la materia fecal en las primeras 48 hs calculado como la suma de los pesos de las heces diarreicas dividida por el peso corporal basal.

Se midieron además el peso total de las heces diarreicas y la duración total de la diarrea.

\section{Resultados principales}

En el grupo Racecadotril, la excreción de materia fecal en las primeras 48 hs fue de $92+/-12$ gr. y en el grupo placebo fue de $170+/-15$ gr.; un $46 \%$ menos $(p<0.001)$. Excluyendo del análisis a las muestras positivas para Rotavirus la diferencia fue un $31 \%$ menos, IC 95\% 16-46\%; $<<0.001$.

Las deposiciones totales fueron $157+/-27 \mathrm{gr} . / \mathrm{kg}$. en el grupo Racecadotril versus $331+/-39 \mathrm{gr} . / \mathrm{kg}$. en el grupo placebo, un $53 \%$ $\operatorname{menos}(p<0.001)$.

La duración media de la diarrea en el grupo Racecadotril fue 28 hs, tanto para los niños positivos como negativos para Rotavirus, mientras que en el grupo placebo la duración fue de 72 y 52 hs, respectivamente.

Los porcentajes de cura a 5 días fueron $84 \%$ en el grupo Racecadotril y $66 \%$ en el grupo placebo.

No hubo efectos adversos importantes en los grupos.

\section{Conclusiones}

En niños con diarrea aguda no sanguinolenta el Racecadotril fue un tratamiento coadyuvante seguro y efectivo.

\section{COMENTARIO}

Este estudio demuestra que el Racecadotril (acetorphan) usado en forma conjunta con las sales de OMS redujo en forma significativa la excreción de materia fecal a las 48 hs, la excreción total, la duración y la cantidad de sales de rehidratación consumidas. Probó además ser efectivo tanto en niños con análisis positivos como negativos para Rotavirus.

El mecanismo de acción de la droga está mediado por la inhibición de la encefalinasa. El aumento de la concentración de encefalinas produce la estimulación de receptores opiáceos $d$, que reducen los niveles de AMPc, lo opuesto al mecanismo de acción de la toxina colérica. Lo anterior da como resultado la secreción disminuida de agua y electrolitos sin afectar la motilidad intestinal, cosa que sí hacen los opiáceos usados como tratamiento sintomático, a expen- sas de la estimulación de receptores $\mu$.

Ya hay experiencia previa con el agregado de esta droga al tratamiento convencional de la diarrea aguda y aparenta ser una alternativa eficaz y efectiva ${ }^{1}$. Si bien el tratamiento indicado para la diarrea aguda sigue siendo la rehidratación oral instaurada en forma temprana, el agregado del racecadotril como coadyuvante resulta interesante, en vista de la marcada reducción de la duración del cuadro tanto en los pacientes positivos a rotavirus (de 72 a 28 hs) como de los negativos (de 52 a $28 \mathrm{hs}$ ) y los porcentajes de curación a 5 días. En países en vías de desarrollo, esto puede representar un potencial impacto en la disminución de la mortalidad infantil debido a esta causa, que mundialmente provoca 3.2 millones de muertes al año. 